\title{
Sobre o Conceito do Rosto do Filho de Deus: A Inexplicabilidade de Uma Perda Sem Nome
}

\author{
Alessandra Montagner ${ }^{1}$
}

\begin{abstract}
Resumo
O presente artigo visa revisitar a experiência vivenciada pela autora enquanto espectadora de Sobre o Conceito do Rosto do Filho de Deus, da companhia teatral italiana Societas Raffaello Sanzio. A autora descreve, detalhadamente, os momentos e sentimentos que compuseram aquela experiência, e utiliza-se de aspectos da teoria teatral contemporânea para criticamente analisar, e embasar, o desconforto e frustração experienciados por ela.
\end{abstract}

Palavras-chaves: Societas Raffaello Sanzio, Espectador, Experiência, Desconforto

\begin{abstract}
The present essay aims at the revisitation of the author's personal experience as a spectator of On the Concept of the Face, Regarding the Son of God, by the Italian theatre company, Societas Raffaello Sanzio. The author describes, in detail, the moments and feelings comprising that experience, and utilises aspects of contemporary theatre theory to critically analyse, and support, the discomfort and frustration experienced by her.
\end{abstract}

Keywords: Societas Raffaello Sanzio, Spectator, Experience, Queasiness

\section{Resumen}

Este artículo tiene como objetivo revisar la experiencia vivida por el autor como espectador de Sobre Concept del Rostro del Hijo de Dio, de la compañía teatral italiana Societas Raffaello Sanzio. El autor describe con detalle los momentos y sentimientos que compusieran esa experiencia, y hace uso de aspectos de la teoría del teatro contemporáneo para analizar críticamente y basar las molestias y frustración experenciados por ella.

Palabras-clave: Societas Raffaello Sanzio, Espectador, Experiencia, Malestar

Há mais de dois anos eu me propus a fazer o que aqui refaço. Lancei-me a escrever sobre a intangibilidade e extrema significância de uma experiência, buscando apreender aspectos daquela vivência que me afetaram profundamente no meu comparecimento a uma representação teatral. Retorno à mesma tarefa, pois as marcas daquele evento continuam a viver em mim como uma experiência que me intriga até os dias de hoje, quando por algum motivo curioso ainda me pergunto: que experiência foi aquela, 
como o teatro se fez tão contraditório em mim? Naquela ocasião eu era parte de uma congregação de indivíduos que conjuntamente lotava o auditório do Barbican Theatre em Londres. Enquanto eu adentrava aquele espaço, comigo vinham uma apreensão nervosa e uma curiosidade ansiosa, pois eu havia esperado inquietamente por aquele momento: presenciar e vivenciar o trabalho, o afeto e o efeito do teatro produzido pelo grupo Societas Raffaello Sanzio. Porém, penso que a intensidade de tal expectativa contribuiu para um desfecho frustrante: ao final da representação eu fui expelida do teatro, pelo próprio teatro, com um sentimento contraditório composto de ambos prazer e desconforto. Creio que o prazer que me inundava resultava do domínio hábil do palco e de seus recursos, era o prazer estético adquirido pela apreciação de uma brilhante articulação da cena e seus meios. Por outro lado, confio que a sensação de desconforto, que comigo deixou o auditório, derivou da percepção de que algo a respeito daquela encenação, daquela experiência, parecia estar errado, equivocado, incompleto. Havia naquele trabalho, e em mim, após presenciar este, uma grande falha, um enorme vão, algo que não possuía nome, mas que era definitivamente angustiante. Ao término do evento, eu me encontrava perturbada e estava literalmente transformada! Assim, ambiciosamente, busco retomar nesse texto a intensidade daquilo que atuou sobre mim, e cobiço, nessa performatividade, o apontamento de uma presença ausente que me acompanha neste (exato e pretendido) evento textual: você. Gostaria, portanto, de convidar você, leitor, a embarcar comigo na revisitação daquela experiência. Espero que possamos juntos navegar por aspectos daquele trabalho que me levaram a uma relação receptiva conflituosa e a uma experiência inquietante. Espero que possamos juntos revisitar aqueles momentos agora distantes, mas - ainda potencialmente presentes.

Estimado leitor, para fazer-te embarcar nesta experiência, penso ser importante desenvolver uma descrição detalhada do que aconteceu naquele palco, naquela noite - saliento que tal descrição será limitada pela minha perspectiva e percepção pessoal. Descreverei tal evento teatral em ordem cronológica, e o farei conjuntamente com uma reflexão teórica de cada um dos momentos e sentimentos que compuseram tal vivência - teorizarei sobre a experiência. Consequentemente, traçarei relações entre tais perspectivas pessoais e um tipo de teoria teatral que possa vir a ajudar-me, e ajudar-te, na compreensão da comiseração que experienciei naquele evento. Portanto, perguntemo-nos: qual foi a origem de tal emoção conflituosa? Do que se 
tratava aquele sentimento? Que mecanismos, naquela representação, me levaram a uma resposta conturbada perante este, e por quê? Por que eu me encontrei dividida entre apreciação e perturbação? Ao olhar para possíveis respostas a estas perguntas, procederemos (eu e você) com a dissecção e resgate daquela vivência e do que tal evento consolidou em mim, enquanto expectante e espectadora deste.

Às 19 horas e 40 minutos de uma Sexta-Feira Santa, uma grande multidão ocupava o auditório do teatro do Barbican Centre, na expectativa da apresentação de Sobre o Conceito da Face do Filho de Deus, da companhia de teatro italiana Societas Raffaello Sanzio, sob direção de Romeo Castellucci. Naquela peregrinação inicial, eu me encontrava em estado de grande apreensão. Tal sentimento se construiu, provavelmente, por uma mistura da importância do trabalho de Castellucci, e sua companhia, no terreno do teatro contemporâneo e da influência destes na minha pesquisa. Societas Raffaello Sanzio vem desempenhando um papel importante na prática teatral contemporânea, produzindo trabalhos teatrais chocantes e perturbadores - os quais eu não havia tido a oportunidade de experienciar até aquela noite, mas nos quais eu estava, obviamente, muito interessada. Por estas circunstâncias e apreensões, caro ledor, a perspectiva de vivenciar o trabalho da Societas Raffaello Sanzio era grande o suficiente para me levar a um estado de ansiedade e descompasso antes mesmo do início da primeira cena. $O$ desejo pelo encontro com aquela experiência, com a falada perturbação do trabalho de Castellucci, era vivo e pujante dentro de mim. Eu era uma espectadora entusiasta do que eu ainda não conhecia ou poderia prever - enquanto me perguntava como me relacionaria com aquilo. Por conseguinte, a intensidade da experiência adquirida através daquele encontro teatral resultou tanto de sentimentos que precederam, quando de emoções que sucederam a cena. Tal vivência, e suas intensidades, compõem a problemática central do presente artigo.

A representação iniciou-se às 19 horas e 45 minutos. As cortinas já se encontravam abertas e o elemento que anunciou o início da cena foi a tradicional mudança na iluminação do teatro, quando o público é lançado dentro da escuridão do auditório enquanto o palco se eleva a um pedestal de luz. A audiência foi apresentada a um palco que abrigava dois mundos contrastantes. Num primeiro plano, o cenário introduzia um ambiente que claramente delineava uma casa ordinária, mobiliada com sofás, uma televisão, uma pequena mesa e uma cama. Estes elementos foram dispostos no palco como seriam em uma casa comum, definindo ambientes - por 
exemplo, sofás e televisão são peças do mobiliário que, normalmente, compõem uma sala de estar. Contrastando tal construção realista (leitor, peço-lhe que entenda que eu emprego tal adjetivo, na classificação das escolhas referentes ao mobiliário cotidiano, sem qualquer pretensão de conectar o que havia no palco, durante a representação, ao conceito estético do realismo no teatro) do espaço de representação, havia ao fundo uma imagem enorme da face de Jesus. Um quadro dilatado da face cristã que se reproduz pelas paredes das casas de muitas famílias católicas ao redor do mundo.

Havia, desde o primeiro instante do meu encontro visual com Sobre o Conceito do Rosto do Filho de Deus, uma divisão conflituosa naquele trabalho. O choque de dimensões entre o mobiliário cotidiano e o rosto gigante de Jesus Cristo consistia em uma união de tamanhos e componentes que desrespeitavam regras de harmonia quando justapostos. Todavia, tais incoerências harmônicas são facilmente abrigadas pelo palco, quando úteis à representação. Neste caso, eu estava definitivamente disposta a entender a razão de tal contradição, e dependia de uma articulada transação, entre o meu olhar e o que eu via, para apreender esta incoerência.

From a performance's opening moments, spectators engage in the process
of scanning the stage and its activities, looking for material from which
they can elaborate a narrative framework, corroborating this data with their
expectations and what they have already formulated. (...) Facts link with
facts, and this interplay of information enables comprehension to construct a
network of events and relationships (GARNER, 1989, p. 11).

Através desta negociação entre o eu-espectadora, a realidade física do palco, e o enredo que suavemente começou ser sugerido por aqueles elementos, o meu entendimento daquela encenação começou a ser tecido por uma rede de percepções e associações. Tais cognições se construíam enquanto a representação progredia. Neste processo de colaboração perceptiva, direta e simultânea, a ação, que os atores estavam prestes a realizar, seria tão importante quanto todo o restante dos elementos cênicos na apreensão da acepção daquele trabalho.

A trama iniciou-se com um ator idoso assistindo televisão. Poucos minutos depois, outro ator adentrou o palco e o universo ficcional do trabalho começou a ser desvelado. As personagens representadas pelos atores eram a de um pai e um filho. Aparentemente, personagem $\mathrm{F}$ (the father) requer constante assistência, pois quando personagem S (the son) está prestes a sair de casa para ir trabalhar, $\mathrm{F}$ mostra sinais de mal-estar. Ao ajudar seu genitor, $S$ percebe que seu pai havia defecado nas suas fraldas geriátricas. A circunstância introdutória do conflito fez-se, então, revelada: F era 
um homem incontinente, que havia perdido o controle de suas entranhas e necessitava de frequente auxílio. S era aquele que oficialmente cuidava e assistia seu genitor. A incontinência da personagem do idoso repetiu-se inúmeras vezes, em recorrências ininterruptas que direcionaram a ação a um clímax repugnante. Tais repetições, então, passaram a ocorrer em intervalos menores, aumentando a tensão entre aquelas duas personagens. No início, S tenta lidar com a situação pacientemente, tentando confortar F e constantemente reafirmando que a sua incontinência não é um problema; porém, $\mathrm{F}$ demonstra-se envergonhado. Toda vez que $\mathrm{F}$ defeca, $\mathrm{S}$ remove cuidadosamente a sua fralda suja, limpa o traseiro de F, o veste com uma fralda nova, e limpa a área de mobiliário e do piso afetada pelo excremento de F. Entretanto, a repetição descontrolada dos episódios de incontinência, faz com que a calma de S dê lugar ao desespero de um ser humano acuado por tal situação sacrificante.

Naquele momento a presença da face de Jesus Cristo ao fundo da cena foi para mim uma forte referência à crença (cristã) de que Cristo (ou Deus) é a única consolação para o sofrimento do homem. Ademais, aquela era uma Sexta-Feira Santa, dia no qual cristãos lembram a crucificação de Jesus Cristo e sua morte como um sacrifício exigido para a salvação da humanidade. Como Societas Raffaello Sanzio se comprometeu desde o início de sua prática teatral à iconoclastia (RIDOUT, 2006b, p.178) - a contestação da veneração de imagens e ícones religiosos - eu não pude deixar de vincular o conflito representado naquele palco a uma crítica diretamente endereçada à Igreja Católica. A associação direta entre o conflito humano representado pelas personagens e o conteúdo religioso da imagem sacra passaram a ser elementos que me desestabilizaram. E o fizeram pela proximidade que poderiam ter para comigo (afinal, eu poderia ser aquele filho), transportando-me para uma relação catártica e conflituosa de identificação e repulsão para com aquela representação teatral e aquele ícone gigante.

A recorrência dos episódios de diarreia, fortemente presentes até este ponto da encenação, foi o elemento inaugural da possibilidade de uma narrativa, e ofertou-me, enquanto espectadora, a ilusão de um contexto e um universo dramático. O que eu vi no palco através do labor dedicado e incondicional de S para com $F$ foi a apresentação de um enredo, um conflito dramático, o qual eu pensei que seria explorado em profundidade ao longo do (esperado) desenvolvimento da trama. Senti-me emocionada pela sensibilidade e delicadeza daquela situação. Aquela era uma condição bastante 
grotesca para um indivíduo, mas também suficientemente real e comum. A incontinência de F era uma das grandes tragédias da vida, um trágico episódio na história de qualquer ser humano: o envelhecimento resultando em dependência e humilhação. Neste caso, aquela era a perda de controle sobre o próprio corpo de uma das formas mais viscerais e abjetas possíveis. Aquela, também era a tragédia de resignação e sacrifício de muitos filhos que dedicam suas vidas a cuidar daqueles que um dia os cuidaram.

A universalidade do sofrimento com tal condição de incontinência fez-me totalmente imersa pelo conflito desempenhado no palco. Eu, leitor, estava imersa em identificação e divagações. Eu já não era mais um membro da plateia. Eu havia me transformado em uma extensão das personagens no palco, um membro atrofiado daqueles corpos em representação, o qual inusitadamente encontrava-se abancado no auditório do teatro. Naquele momento eu estava envolvida e entranhada por um processo de compaixão com a situação de F e S, como que em negação de mim mesma e da minha presença e existência reais. No total abandono da minha condição de espectadora, eu havia sido ludibriada pelas minhas próprias associações com o conflito. $\mathrm{E} 0$ fiz a ponto de estender tais divagações ao meu universo pessoal, e, talvez, aos meus relacionamentos futuros e obrigações para com minha própria família. Eu iria cuidar do meu pai como S estava cuidando do seu?

Evidentemente, como as minhas palavras acabam de descrever, o processo de identificação com as personagens e o conflito estava indo muito bem, eu estava totalmente absorvida pela trama. $O$ evento teatral estava eficientemente operando os seus afetos dramáticos em mim. Eu era confortavelmente parte daquilo. Neste sentido, a encenação foi na verdade uma celebração do que eu aprendi como estudante de teatro: eu havia transcendido o teatro pela minha comoção com a situação das personagens. Eu perpassei o evento teatral e o seu espaço físico em favor da ilusão da narrativa e da credibilidade do enredo. Além disso, eu podia prever o desenvolvimento do conflito e esperava que este acontecesse através de uma narrativa lógica, causal e linear - como uma totalidade explicável.

\footnotetext{
"Dramatic time is, by its aesthetic nature, "meaningful time", and our attempt to discern its temporal outlines and continuities is reinforced by our expectation that we will find them, by our sense that the play's narrative dimension will reveal itself to be a totality, complete in promise even before its detail has been fully articulated" (GARNER, 1989, p. 14).
}

A eficácia do drama era inegável até o instante no qual, repentinamente, algo me despertou. O que é esse cheiro? - eu pensei. Um cheiro forte começou a invadir o teatro, 
um fedor de fezes. Esta merda compareceu com um sobressalto que inevitavelmente me trouxe à consciência de mim mesma como espectadora. Aquele, querido leitor, foi o despertar do meu estado de sonho no auditório. Foi um lembrete de que eu estava em realidade no teatro. Como resultado, o meu mundo catártico de identificação com a trama encenada foi, consequentemente, substituído por uma relação outra que comecei a estabelecer com aquele evento teatral. Eu já não estava mais perdida em assimilação emocional. Eu havia sido denunciada como sendo parte daquela representação, responsável por estar lá. O teatro havia me mostrado a sua natureza mais cruel e ardilosa e, como consequência, me condenado como mais um de seus elementos composicionais. Naquele instante, houve para mim uma mudança na natureza daquela experiência, esta já não se referia à minha absorção e identificação com o universo dramático. $O$ meu principal ponto de atenção, a partir daquele momento, foi a observância dos diferentes mecanismos e elementos que compuseram aquele trabalho teatral, e como eles foram utilizados de modo a afetar a minha relação com aquela encenação.

A intensidade e a verossimilhança do cheiro eram demasiadamente fortes (e reais?) para serem suportáveis. A partir do momento no qual o cheiro me circundou no auditório, prezado companheiro, eu me senti desconfortável. Eu questionei se seria capaz de continuar assistindo aquela representação caso o cheiro ficasse mais forte; o que estava acontecendo. A inserção desse componente sensorial àquela encenação me abateu e perturbou como sendo um instrumento infrator da arte do teatro, confrontando-me perante minha imobilidade enquanto espectadora que se encontrava de alguma forma aprisionada pelo seu assento. A passividade e o conforto da apreciação estética e da identificação emocional com o conflito foram substituídos pela denúncia de mim como participante silenciosa, porém ativa, naquela situação. Fui levada aos limites por aquela trama, bem como indiciada pela observância do teatro. Naquele (meu) clímax da encenação, fui presenteada com o verdadeiro significado da minha emancipação enquanto espectadora. Fui brindada com a responsabilidade que compreende qualquer tipo de emancipação, ou participação ativa, e confrontada com a um teatro ativo que visa articular representação enquanto presença e passividade enquanto atividade (RANCIÈRE, 2009, p.22). Meu ato voyeurístico transformou-se em uma presença ativa, através da qual eu fui impelida em um envolvimento forçado e violento com o espaço teatral. Eu foi denunciada ao teatro e delatada a mim mesma. Comprei o ingresso e assinei o contrato para um dos trabalhos de Castellucci e esperei 
ansiosamente por aquele momento, o que eu pensava que aconteceria, então? Por que eu assistiria aquele trabalho, leitor, senão para vivenciar o desconforto e perturbação do teatro da Societas Raffaello Sanzio?

Embora eu houvesse aceitado o acordo de estar no teatro e vivenciar aquele trabalho e seus elementos, a minha resposta imediata para com o cheiro de fezes era uma que se referia à ofensa. O primeiro pensamento que me veio à mente foi: eu não posso acreditar que ele (Romeo Castellucci) vai nos expor a isto! Logo após esta primeira reação, ledor, eu conjeturei que Castellucci estava brincando com o jogo do teatro, o jogo do "faz-de-conta" (RIDOUT, 2006b), e o estava fazendo da forma mais séria e profissional possível. Societas Raffaello Sanzio estava honrando sua reputação de comprometimento estrito para com a prática teatral, ao ponto de o teatro, naquele momento, tornar-se real. Em Sobre o Conceito do Rosto do Filho de Deus o teatro estava funcionando e me levando a acreditar que o "faz-de-conta" era real (KELLEHER e RIDOUT, 2006b, p 13.). O teatro pode suceder como um meio de representação apenas através dos mecanismos de representação (RIDOUT, 2006a), e se fezes fedem na vida real, por que elas não poderiam feder no teatro?

Tais impressões, sentimentos e interrogações, fizeram com que eu me questionasse sobre a natureza e a ética do trabalho de Romeo Castellucci; bem como o caráter de um evento teatral. No livro Stage Fright, Animals and Other Theatrical Problems (2006a), Nicholas Ridout disserta sobre questões que tradicionalmente são deixadas de fora das discussões relativas à teoria teatral. Estes temas se referem aos momentos nos quais o teatro "fracassa", às falhas do meio que em realidade revelam a sua verdadeira natureza. De acordo com Ridout:

\footnotetext{
There is something wrong with theatre. You watch it happening. You are there and its 'hidden face' is in your face. You are one of the 'accessories'. The theatre is structured upon the face-to-face encounter, and it is around the ethical, aesthetic and political problems of such encounter that the wrongness of theatre appears and organises itself. The theatre does its work while you watch. In the theatre you always know you are there, at the scene of the action, at the site of production. Seeing yourself there, and others there, and facing up to the nature of your relationships with these others, is what disquiets the mind and degrades the art (RIDOUT, 2006a, p. 29)
}

Foi assim que eu me vi delatada naquela articulação teatral: eu era simplesmente mais um dos muitos "acessórios" do maquinário através do qual o teatro se constrói. Assim como aquele mau odor, eu, espectadora, era apenas mais um dos elementos do teatro. Eu fui apontada ao teatro enquanto este se apontava a mim. O teatro revelou-se na minha presença e através desta. Não existia realidade, sofrimento ou conexão reli- 
giosa no palco. Havia apenas uma maestria competente e eficaz do fazer teatral. Consequentemente, este domínio hábil do palco e a brilhante implementação dos recursos teatrais (o cheiro, eu, etc.) consiste, a meu ver, no que Romeo Castellucci chama de "despertar.' Para ele, o teatro contemporâneo consolidou-se como uma experiência de sensibilização da consciência. Consciência em termos de abertura, consciência a respeito do que se abre (CASTELLUCCI, 2007, p.4). Seu conceito do "despertar" através da experiência teatral, e a maneira como ele utiliza tal entendimento para promover a revelação dos mecanismos teatrais, são observações que se materializaram através do mau cheiro em Sobre o Conceito do Rosto do Filho de Deus. Este trabalho ofertou-me o teatro em seus aspectos mais amargos e doces. O meio teatral desvelou-se aberta e claramente diante do meu olhar, da minha presença e do meu testemunho - os quais haviam previamente sido iludidos pelo mundo dramático - e eu considerei isto brilhante.

O que aconteceu após o meu despertar, foi uma interrupção ainda mais agressiva, leitor. Durante a parte final da encenação, ambos os personagens, F e S, deixaram o palco e suas presenças foram substituídas pela celebração do maquinário utilizado para suspender a foto do ícone Jesus. O que existia por detrás do rosto de Cristo foi despejado ao olhar dos espectadores. Um jogo técnico iniciou-se, com a gigantesca foto sacra sendo esticada, estilhaçada e balançada pelos técnicos que se encontravam suspensos atrás dela. Um líquido (fezes?) começou a escorrer pela face de Jesus. $\mathrm{O}$ rosto foi então despedaçado, rasgado, e as palavras You are (not) my shepherd foram reveladas ao auditório. $\mathrm{O}$ evento direcionou-se ao seu encerramento, com um forte piscar de luz, vindo de uma das coxias, e, em seguida, com os espectadores sendo iluminados no auditório enquanto o palco retornava para a sua escuridão.

Eu vivenciei o encerramento da encenação como uma dissolução abrupta, e interrupção violenta, da trama antes de sua resolução. Tal quebra não acrescentou nada à delicadeza da relação entre pai e filho. $\mathrm{F}$ e $\mathrm{S}$ deixaram o palco sem concluir seus destinos, sem apresentar nenhuma saída conclusiva àquela situação comovedora na qual eles haviam me envolvido. O estado de absorção pelo mundo dramático do palco foi abortado de mim, principalmente, pela inserção do cheiro, e tal interrupção foi reforçada pela incompletude do enredo. Eu queria saber mais sobre aquele conflito humano e familiar. Em contraste, eu fui presenteada com a violação do desenvolvimento e progressão do enredo e com a face de Jesus sendo vomitada na minha face. Assim como as fezes que saíam do corpo de F, a figura de Jesus assemelhava-se à 
presença sem importância de um outro que serve apenas para confirmar a nulidade do seu comparecimento naquele evento. Eu acolhi o jogo manipulatório do rosto de Cristo como a sublimação da alteridade (Ridout, 2006a) caracterizada pela presença de um animal (um "outro" que é muito diferente de mim) no palco. Eu acredito que a ênfase dada à face de Jesus desconhece a função da sua existência e não é capaz de teatralmente envolver uma audiência humana, a qual comparece ao teatro para experimentalmente conceber a condição de sua própria humanidade (Ridout, 2006a, p.98).

Além disso, tal conclusão incompleta da encenação fez com que eu me sentisse enganada. A interrupção do estado de absorção e identificação, para a qual a situação "pai e filho" me transportou, foi sentida como uma decepção. Eu havia me identificado profundamente com o conflito esboçado pela primeira parte do trabalho, eu havia investido emocional e esteticamente na minha relação com aquele conflito. Como resultado, eu esperava por uma resolução para a trama entre F e S. Entretanto, eu fui traída! A interpelação total da continuidade do enredo significava, para mim, a completa ruptura e defloramento de uma condição humana que, por ser humana, necessitava de uma continuação, conclusão e totalidade (será?). Neste caso, tal terminação me introduziu a um grande sentimento de desapontamento e frustração.

A descontinuidade do enredo e a frustração por ter as minhas expectativas ludibriadas, também equivaleram à traição do enredo dramático. No livro Postdramatic Theatre (2006), Hans-Thies Lehmann disserta sobre o divórcio entre o drama e o teatro na prática teatral das ultimas décadas do século $\mathrm{XX}$. Ele coloca que tal ruptura agiu como tendência adotada por diferentes artistas da vanguarda teatral. Segundo Lehmann, faz parte da constituição deste tipo de teatro:

To hurt feelings, to produce shock and disorientation, which point the spectators to their own presence precisely through 'amoral', 'asocial' and seemingly 'cynical' events. In doing so, it deprives us neither of the humour and shock of cognition, nor of the pain nor the fun which alone we gather in the theatre (LEHMANN, 2006, p.187).

Precisamente, isso é o que eu acredito ter acontecido comigo. O estado perturbador da incompletude do enredo sugerido (drama) me deixou desatinada, me fez solitária na tentativa de explicar racionalmente o enredo. O teatro havia fracassado nos seus anseios tradicionais e aristotélicos. Eu sempre considerei este fracasso brilhante em termos teóricos, mas naquela noite este também provou ser, em realidade, agitador. Acredito que a maestria de Romeo Castellucci ao lidar com os componentes do palco (quando unindo, discernindo e agrupando estes elementos a fim de construir efeitos sensoriais que 
possam afetar e desestabilizar o espectador), na sua produção artística, é incompreensível para a lógica racional da mente e do jogo dramático, mas muito apropriada para a realidade do evento teatral. Ele utiliza o meio teatral para que este trapaceie um de seus maiores afiliados: o drama. Ele atraiçoa o drama para desvelar o teatro como a ferramenta fundamental do evento teatral. Ele trai o drama talvez porque o drama tenha traído o teatro, quando, por tempo suficiente privou este da posição de grande astro do palco.

Quando a encenação havia acabado e as luzes estavam acesas, eu não ansiava aplaudir o que eu havia presenciado. Eu não queria honrar o contrato teatral e finalizá-lo com o presente do aplauso (Ridout, 2006a); talvez porque o que eu ganhei daquela experiência não foi uma revelação, mas um problema. A minha sensação no final daquela representação teatral não foi de satisfação ou plenitude, mas sim de fragmentação. Eu estava perdida no vazio de uma perda sem nome. Minha fantasia e ilusão foram interrompidas pelo mundo sensorial do teatro e, por isso, eu me perdi nos terrenos da inexplicabilidade. Por não finalizar um conflito dramático, Romeo Castellucci me apresentou um novo conflito: a impossibilidade de compreender racionalmente, apreender e nomear a minha experiência como espectadora e, inevitavelmente, participante de Sobre o Conceito do Rosto do Filho de Deus. A incompletude daquele enredo significava a não plenitude da minha experiência.

Caro companheiro, coincidente e coerentemente, a angústia que me acompanhava enquanto eu deixava o Barbican Theatre, naquela Sexta-feira Santa, é o mesmo sentimento que eu tenho comigo agora, na conclusão deste artigo. O sentimento perturbador e sem nome que eu experienciei após aquele evento ainda se faz anônimo e inquietante. A frustação referente à incapacidade de nomear minha experiência diante do trabalho de Castellucci é o mesmo desapontamento que se faz meu companheiro neste momento. Não ser capaz de compreender aquela vivência se assemelha ao aborto de algo que eu nunca possuí, o abandono daquilo que eu nunca cheguei a conhecer. Eu deixei o auditório do Barbican Theatre naquela noite enquanto $\mathrm{F}$ e $\mathrm{S}$ deixavam o palco, e mesmo com tanta coisa tendo acontecido entre nós nada foi dito. O nosso encontro intenso e a nossa partilha sensual e agressiva tornaram-se história. Eu não era capaz de reverter aquela experiência e não podia fazer nada para mudar isso; pois o fato, o evento, (qualquer que seja o nome que lhe pareça mais adequado) era irreversível.

Conclusivamente, por todas as razões apresentadas, esboçadas e explicitadas, e especialmente por toda a angústia, perturbação e inquietação que derivaram destas, 
eu realmente acredito que a experiência descrita através das linhas anteriores ilustra nada mais do que uma contradição que é inerente à (real) natureza do teatro. Este amor conflituoso ou ódio perturbador, este desconforto intenso e estético para com a arte teatral são, como diz Nicholas Ridout, uma prova do seu sucesso e um componente de sua natureza:

This ambivalence certainly characterises my own relationship with theatre. Theatre, being queasy, makes me queasy. That such queasiness is widespread, that we find theatre uncomfortable, compromised, boring, conventional, bourgeois, overpriced and unsatisfactory most of times is I think not only generally accepted as true, but also generally accepted as part and parcel of the whole business. Theatre's failure, when theatre fails, is not anomalous, but somehow, perhaps constitutive. (RIDOUT, 2006a, p.3).

Constitutivo, talvez porque promova a discussão de ideias preconcebidas e anseios reprimidos, o despertar da consciência e presença adormecidas na era do conforto mediático, e a perturbação do comparecimento, assim como o que Sobre o Conceito do Rosto do Filho de Deus fez comigo? Talvez. De qualquer modo, o que perdurou comigo foi uma perda anônima e incompreensível, uma impossibilidade comunicativa, um desconforto inquieto, uma terminação catastrófica de... (algo que ainda se faz anônimo em mim!).

\section{Referências Bibliográficas}

CASTELLUCCI, Claudia e Romeo; GUIDI, Chiara; RIDOUT, Nicholas; KELLEHER, Joe. The Theatre of Societas Raffaello Sanzio. London. Routledge: 2007

GARNER, Stanton. The Absent Voice: Narrative Comprehension in The Theatre. Michigan. University of Illinois Press: 1989.

LEHMANN, Hans-Thies. Postdramatic Theatre. Abingdon. Routledge: 2006.

RANCIÈRE, Jacques. The Emancipated Spectator. London. Verso: 2009.

RIDOUT, Nicholas. Stage Fright, Animals and Other Theatrical Problems. Cambridge. University Press: 2006a.

Nicholas. Make-believe: Socìetas Raffaello Sanzio Do Theatre. In KELLEHER, Joe; RIDOUT, Nicholas (eds). Contemporary Theatres in Europe: a critical companion. London, Routledge, 2006b, p. 175-187. 